\title{
Analysis on Protection and Development Mechanism of Traditional Ancient Villages in China
}

\author{
Li Chang \\ Xi'an University of Architecture and Technology Huaqing College, Shaanxi, Xi'an 710043
}

Keywords: traditional ancient villages; protection and development; intrinsic and extrinsic factors

\begin{abstract}
This paper mainly simply introduces traditional ancient villages in China, first indicates the problems existing in protection and development of traditional ancient villages at present, then makes analysis from the perspective of intrinsic factors, and finally specifically analyzes the current protection and development mechanism of ancient villages from the perspective of extrinsic factors.
\end{abstract}

\section{Introduction}

The farming civilization of traditional ancient villages is the most direct embodiment, and represents inestimable historical, cultural, economic values, etc. However, the economic level improvement is accompanied with the acceleration of urbanization; the traditional ancient village civilization has been dying day by day, and has attracted the attention of various people. Therefore, it is necessary to strengthen protection and development of ancient villages, and analyze, by analyzing current problems, how to better enable traditional ancient villages to play a better role and promote the development of ancient civilization.

\section{Analysis on problems existing in protection and development of traditional ancient villages in China}

\subsection{Imperfect interest coordination mechanism}

The protection of ancient villages involves many contents, such as the development of economy, culture, water conservancy, forestry, township enterprises, tourism, etc. However, due to the management system problems, the situation of poor management takes place, and external investment cannot be effectively utilized. Especially, in the development of ancient villages in recent years, development of the tourism industry can bring maximum economic benefits, but due to the defects of the management system, the investment intention of commercial investors is reduced, and the tourism industry slowly develops, so that the development and protection of all ancient villages is stopped. Influenced by historical factors, the property rights of ancient villages are not clear, so that it is difficult to transfer ancient villages, difficult to trade ancient villages, and impossible to effectively attract social capital to protect the development of ancient villages. Moreover, due to lack of an effective coordination mechanism, even if villagers have signed agreements with investors, it is still difficult to solve many disputes. Therefore, the government must promote to improve the interest coordination mechanism, and protect the villagers' interests and the development of ancient villages through a perfect system.

\subsection{Adverse impact of economic development on promotion of development of ancient villages}

The economic development drives gradual improvement of the people's living standards. The modern production and life style has changed the habits of villagers in ancient villages, and is greatly different from the traditional life style. Moreover, the house buildings in traditional ancient villages have been damaged or shabby due to the influence of natural and human factors and the like, some old infrastructure has not complied with the modern people's life habits, and the improvement cost has exceeded the replacement cost. Therefore, villagers are more accustomed to rebuilding, rather than renovating, their houses and other infrastructures, thereby greatly affecting 
the development and protection of ancient villages. In addition, the unique architectural patterns of traditional ancient villages and the natural environment reflected therein are excellent cultural heritage for mankind, and are not renewable once destroyed. Therefore, these problems existing in traditional ancient villages must be addressed, and attention shall be paid to protection of building groups in ancient village by housing construction at additional sites. The governments shall provide funds for regional management and restoration of buildings in ancient villages, so as to protect the development of ancient villages.

\section{Analysis on intrinsic factors of protection and development of traditional ancient villages in China}

Traditional ancient villages play an important role in the long history of the Chinese nation, and will usually experience four development stages: emergence, development, thriving and decline. By analyzing the characteristics of each stage, it can be found that the development of traditional ancient villages in China is an internally emerging style, and its own characteristics are principal factors. There have been traditional ancient villages since ancient times. In the feudal society, usually a village also represented a family name tribe. Even if in a modern village, there is still the situation that there is the same family name, but there is not a kinship between everyone in a modern village, which is greatly different from the relationship between ancient villages. In particular, the management system of feudal society is the system of prefectures and counties, and the clan village mode is more conducive to centralized management of the rulers and conducive to implementation of the punishment mechanism, which plays an important role in consolidating the state power.

Today, some ancient villages having valuable cultural heritages still exist in China, which cannot be separated from village regulations and non-governmental agreements possessed thereof. For example, at present, Nanxi River in Wenzhou of Zhejiang still follows the village regulations and non-governmental agreements of traditional ancient villages, involving relevant contents of environmental protection. Even after hundreds of years or thousands of years of development, these still comply with the current social development trend, are put in the most important position of modernization, have been incorporated into the national development strategy, and become an important development goal. These to be done urgently by modern people have been very extremely effectively implemented as early as in the development and civilization of ancient villages of China.

However, with the fast change and development of modern society and growth and life of teenagers and children in big cities like armored concrete since childhood, it is impossible to realize the unique cultural tradition of ancient villages, and the internally emerging emotional sustenance no longer exists. Due to the convenience brought by modern life, people also have lost their desires to live in ancient villages, and pursue and yearn for prosperous metropolis being able to bring greater benefits. Therefore, the development prospects of ancient villages are worrying. With the era changes, the clan village pattern has gradually been edged out of the historical stage. With the destruction and idling of buildings in ancient villages, it is necessary to protect the traditional cultural heritage of ancient villages. Lack of education and publicity, and exploration of and support for the new development path of ancient villages are the main reasons for this situation. Especially, if the rapid development of modern society just relies on the spontaneous behaviors of villagers, it is not only impossible to improve the living quality of villagers, but also impossible to realize protection of ancient villages. Therefore, it is necessary to pay attention to introducing external mechanisms, so as to promote new industry development and improve the economic benefit by external driving forces, whist promoting the protection and development of ancient villages.

\section{Analysis on extrinsic factors of protection and development of traditional ancient villages in China}

As mentioned above, in order to strengthen protection and development of traditional ancient 
villages, it is necessary to attach strengthened importance to extrinsic factors. What are main extrinsic factors? How to promote the development of ancient villages is to be discussed by us. In this paper, the author mainly analyzes two aspects as follows.

\subsection{Follow the market orientation effect}

Many unique building styles and characteristic cultural conventions in ancient villages are important attracting magic weapons. In particular, in the context of prevailing tourism industry at present, people pursue more of primitive culture and traditional customs, and thus the original ancient villages are also more able to attract the attention of tourists. Nowadays, some variety shows are also strengthening introduction and propaganda of ancient villages, thereby resulting in a tourism upsurge and playing an important role in protecting traditional ancient villages. However, whilst introducing market mechanism to reform the development situation of ancient villages, attention should also be paid to some problems existing in practice. The market orientation effect is accompanied with enterprises' getting involved in development, which will lead to disputes between the enterprises' interests and the villagers' interests, and is also the issue of how to deal with ownership and management rights, in order to prevent the phenomenon that the ancient villages are developed and economic benefits are achieved, but the villagers still fail to gain any interests. Therefore, the author suggests implementing a fair income distribution mechanism, so that the villagers can also enjoy the benefits brought by tourism. This can better stimulate the enthusiasm of the villagers, supervise and urge them to better make contributions to the development of the tourism industry in ancient villages. Furthermore, attention should also be paid to the problem of environmental capacity, and environmental problems are problems that must be taken seriously in the economic development at present. The development of the tourism industry in ancient villages aims to adapt to the market development mechanism, so as to better protect the ancient villages. Therefore, it is necessary to strengthen supervision of the management and organization system, protect the environment of ancient villages through detailed analysis on the capacity of ancient villages to accommodate tourists, and prevent ancient villages from losing their own characteristics.

\subsection{Strengthen support by governments at all levels.}

The development of any industry is inseparable from the government support. The traditional ancient villages are an epitome of the excellent culture of the Chinese nation, and should be taken seriously by state organs at all levels. Besides, improving the living standards of local villagers is also the government's responsibility. Therefore, the author thinks that the government can provide support from two aspects as follows: 1) increasing fund investment: it has put forward hereinbefore that for long years out of repair and due to the influence of natural and human factors, ancient villages are severely damaged, and therefore the government needs to increase fund investment in repair and reconstruction of ancient villages. At the same time, development of the tourism industry requires convenient transportation. In order to develop the tourism industry, attention must be paid to development of transport facilities, and the government must provide enough support for construction of the transport infrastructure; 2) strengthening the government's policy support and macro management: with the importance attached to the traditional culture development level in China in recent years, the government must formulate corresponding laws and regulations to protect traditional culture. As the carriers of traditional culture, ancient villages also need the government's policy support. The government support plays a role in guiding enterprises' investment in development of ancient villages, and the government provides a more solid guarantee for development and investment of enterprises by the provisions of previous laws and regulations and the macro-guidance through future policies.

\section{Conclusion}

The development of traditional ancient villages has aroused the attention of China, the society and other aspects. It is necessary to strengthen protection and development of ancient villages, and 
give full play to the excellent cultural traditions possessed thereof. Through protection and development of ancient villages, the modern civilization achievements and the traditional culture are integrated to better solve the existing problems and realize the revival of ancient village civilization.

\section{References}

[1] Wang Jun \& Liu Yuqian. Current Situation and Enlightenment of Traditional Village Protection in Suzhou City [J]. Informatization of China Construction, 2017 (3): 56-61.

[2] Zhao Huaqin, Jiang Yong and Wang Feng. Innovative Practice of Protection and Development Mechanism of Ancient Villages in Zhejiang Province [J]. Development of Small Cities \& Towns, 2015 (9): 44-46.

[3] Ye Changsheng. Discussion on Challenges and Development Paths in Protection of Ancient Villages [J]. Art Science and Technology, 2014 (12): 25-27. 